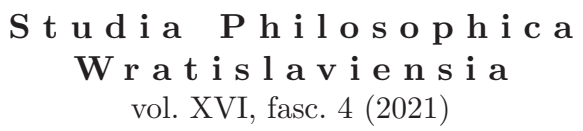

\author{
WOJCIECH GAMROT \\ ORCID: 0000-0001-5617-2600 \\ Uniwersytet Ekonomiczny w Katowicach
}

\title{
The type individuation problem
}

\begin{abstract}
Lockean justifications of intellectual property postulate the appropriation of immaterial entities, in various contexts called types, patterns, designs, or technologies. It is widely believed that the ownership of such entities gives the owner a right to control their physical embodiments and prohibit imitation. For the prohibition to be meaningful, a condition identifying forbidden objects must be formulated. It must cover not only objects which are identical to some original artifact or its exact, ideal description, but also those which are only similar. This requires systematic answers to three questions: (1) which material structures and which of their subsets should be compared? (2) which of their characteristics should be compared? (3) how to combine these characteristics into a decision rule for token identification? There is no underlying empirical reality that could be independently consulted by individuals in order to incontestably answer these questions. Meanwhile constant evolution in technology and arts requires addressing them repeatedly. Consequently, intellectual property regimes must rely on political institutions incessantly dictating the scope of prohibition, and hence they cannot originate or exist in a prelegal state of nature.
\end{abstract}

Keywords: type, token, boundary, intellectual property, patent, copyright, Locke, natural right 


\section{Introduction}

The abbreviation: "IP" is commonly recognized in contemporary society. It is usually deciphered as Intellectual Property. ${ }^{1}$ The meaning of IP may roughly be characterized as the right to prohibit exact or inexact replication of certain objects, patterns or processes, and to prohibit unauthorized sales and use of replicas. However, naming something a "right" and popularizing the usage of such a designation does not automatically constitute a justification. A theory is needed to explain why anyone should think of IP rights as valid. Meanwhile, according to Abraham Bell and Gideon Parchomovsky, ${ }^{2}$ any coherent and comprehensive theory of property must specify what things are protected. This usually leads to debates on what kinds of objects may be owned. ${ }^{3}$ However, it is not sufficient to point out to the general class of entities that could be eventually appropriated. A theory has to explain the rules of appropriation. It has to specify which objects may be taken into ownership, and in what circumstances. In this paper, three dimensions of this problem are identified. They are universal and pose a challenge to any IP theory, consequentialist and non-consequentialist. It is further argued, that the difficulty is particularly acute in the context of Lockean (or natural rights) IP theories whose starting point is the prelegal, pre-institutional state of nature. The lack of objectively grounded answer to the stated challenge derails these theories.

\section{The Type and its Scope}

There are various activities which refer to inventions or works of art, but are not considered illegal or harmful. The memorizing of an innovation, song or poem that another individual came up with earlier, is generally not considered a trespass.

1 There are also those who maintain that the word "property" is unjustified and that "privilege" or "monopoly" are more appropriate terms, for example: B. Tucker, Individual Liberty, New York 1924, p. 252-256; W. Leggett, Democratick Editorials: Essays in Jacksonian Political Economy, L.H. White (ed.), Indianapolis 1984; T. Sandefur, 'A Critique of Ayn Rand's Theory of Intellectual Property Rights,' The Journal of Ayn Rand Studies 9 (2007), p. 139-161; T.W. Bell, 'Copyright as Intellectual Property Privilege,' Syracuse Law Review 58 (2007), p. 523-546; T.W. Bell, Intellectual Privilege, Arlington 2014; N.S. Kinsella, Against Intellectual Property, Auburn 2008; M. Boldrin, D.K. Levine, Against Intellectual Monopoly, Cambridge 2008; E. Dominiak, 'Anarcho-Capitalism, Aggression and Copyright,' Political Dialogues 16 (2014), p. 37-47.

2 A. Bell, G. Parchomovsky, 'A Theory of Property,' Cornell Law Review 90 (2005), pp. 531-615.

3 Debates on this subject are reflected in various works including: W. Fisher, 'Theories of Intellectual Property,' [in:] New Essays in the Legal and Political Theory of Property, Munzer S. (ed.), Cambridge 2001, pp. 168-199; K.E. Himma, 'The justification for intellectual property: Contemporary philosophical disputes,' Journal of the American Society for Information Science and Technology 59 (2008), pp. 1143-1161; T.G. Palmer, 'Are Patents and Copyright Morally Justified ? The Philosophy of Property Rights and Ideal Objects,' Harvard Journal of Law and Public Policy 13 (1990), pp. 817-865; T. Papaioannou, 'Towards a critique of moral foundations of intellectual property rights,' Journal of Global Ethics 2 (2006), pp. 67-90; R. Uszkai, 'Intellectual Property Has No Personality,' Annals of the University of Bucharest Philosophy Series 66 (2017), pp. 181-205. M. Lambrecht, 'On water drinkers and magical springs: Challenging the Lockean proviso as a justification for copyright,' Ratio Iuris 28 (2015), pp. 1-29. C. Błaszczyk, 'Lockean intellectual property refuted,' Scientia Politica 32 (2020), pp. 161-186. 
Similarly, those who merely contemplate such entities or express an opinion on them are not prosecuted. IP rights are about the control of matter. ${ }^{4}$ They necessarily refer to material structures, that is gatherings of matter arranged in a specific way. ${ }^{5}$ Infringements on these rights are declared when someone organizes material objects in a forbidden manner, offers the resulting material structure or its services for sale, or otherwise profits from it. The prohibition of such activities is enforced regardless of the legitimate prior ownership of cameras, computers, plotters, guitars, chisels and marble by copyists, imitators and authors of derivative works. It is enforced despite the fact that such individuals did not sign any voluntary contract that would oblige them not to perform these specific actions. Therefore, in order to justify the prohibition a conceptual link between the alleged victim of IP violation and material objects in question must be found. Such an abstract representation of morally protected interest is construed as an immaterial type, which is distinguished from material structures that embody it, called tokens. ${ }^{6}$ The identity of a type is determined by the condition that a given object must meet in order to be a token. ${ }^{7}$ The condition can be a conjunction of relations (one-place or many-place), specifying necessary attributes of structure's components and the way of joining them. It may define a particular spatial ordering of components (like transistors in a microprocessor, paper and ink in a book) or a spatiotemporal pattern ${ }^{8}$ (moves of a robot in a productive process, transitions of atoms in a chemical synthesis, sequences of electrical impulses that amount to a program execution in a computer, motion of the body in a ballet and the like). When the type has been declared someone's property, certain kinds of actions with respect to its tokens are widely believed to constitute IP violations, if not authorized by the type owner. Various branches of IP may be characterized under this general conceptual framework. In particular, copyright governs "expressions of ideas" corresponding to types instantiated in books, photos, paintings, and songs. Similarly, patents govern "practical applications of ideas" corresponding to types instantiated in mousetraps, dishwashers, and lasers. Other kinds of IP regulations covering trade marks, industrial designs, databases,

4 J. Hughes, 'The Philosophy of Intellectual Property,' Georgetown Law Journal 77 (1988), pp. 330-350. See also: H. Breakey, 'Natural intellectual property rights and the public domain,' The Modern Law Review 73 (2010), pp. 208-239; R. Uszkai, 'Are Copyrights Compatible with Human Rights?' The Romanian Journal of Analytic Philosophy 8 (2014), pp. 5-20.

5 The terminology and reasoning presented in this section closely follow the argument of W. Gamrot, 'The Type-Token Distinction and Four Problems with Propertarian IP Justifications,' Axiomathes (2021), https://oi.org/10.1007/s10516-021-09564-5.

6 Such terminology is adopted by numerous scholars including authors of the following works: A. Moore, 'Lockean Theory of Intellectual Property,' Hamline Law Review 21(1997), pp. 65-108; J. Dodd, 'Musical Works as Eternal Types,' British Journal of Aestethics 40 (2000), pp. 424-440; J. Dodd, Works of Music: An Essay in Ontology, Oxford 2007; L. Biron, 'Two Challenges to the Idea of Intellectual Property,' Monist 93 (2010), pp. 382-394; J. Wilson, 'Ontology and the Regulation of Intellectual Property,' Monist 93 (2010), pp. 450-463; R. Uszkai, 'The Use of Torrents in Society,' Libertarian Papers 10 (2018), pp. 181-210; S. Luper, 'Natural resources, gadgets and artificial life,' Environmental Values 8 (1999), pp. 27-55.

7 J. Dodd, 'Musical Works: Ontology and meta-ontology,' Philosophy Compass 3 (2008), pp. $1113-1134$.

8 W. Gamrot, 'On type creation and ownership,' Political Dialogues 30 (2021), pp. 187-200. 
animal breeds and plant varieties also refer to various types. Hence the type-token distinction enables a description of IP as a generic category ${ }^{9}$ that may be recognized in diverse contexts including currently existing legal regimes as well as other postulated or hypothesized theoretical possibilities. This forms a convenient foundation for universal, widely applicable deductions.

Theoretically, one may define types at any level of generality. In particular, this includes types that specify complete layouts of material structures with perfect accuracy. They may be called exact, exhaustive, or elementary. Tokens of such a type differ only with respect to their spatial location - as distinct material objects cannot occupy the same place in space - but otherwise they are indistinguishable. Any modification of a token would entail the loss of token status: the structure would no longer comply with type's exact condition. An opposite logical extreme corresponds to a type whose condition is the most general. Such a trivial catch-all super-type is embodied in any material structure. There is no physical modification that could deprive the structure of the token status. Between these two extremities there are many other possibilities to choose from. Let us start with observing, that it makes very little practical sense to consider ownership of individual exact types. Precise specification of such a type, production of tokens that satisfy its condition and verification of compliance are either prohibitively costly, or not technically possible. Moreover, there are no grounds for declaring IP violation, when even the results of deliberate copying fail to meet type's exact condition. Minor distortions not affecting structure's benefits can always be arranged purposefully to bypass proscription. This defeats any economic motivation for IP, even for types which are not exact, but determine exactly certain characteristics of material structure, as shown in the example 1.

EXAMPLE 1: If the type involves a beneficial combination of two substances (say M and N) mixed in the prescribed proportion $f=0.6$, so that exactly 6 parts of $\mathrm{M}$ are combined with 4 parts of $\mathrm{N}$, then a mix of these ingredients in the proportion $f^{\prime}=0.5999$ does not conform to the type's condition and is not prohibited, but most likely retains similar usefulness. The type is not even exact, as it does not determine completely the spatial distribution of the mix. But it is still pointless to own it. ${ }^{10}$

The example demonstrates, that in order to ensure practicality and enforceability of an IP regime one must necessarily appropriate types in a way which permits prohibiting whole classes of similar material structures. Therefore, type conditions cannot be exact. They must define - in not too strict terms - only certain aspects of the structure, leaving others unspecified. Therefore, a natural question is: what should be the scope of such an type? Daniel Attas ${ }^{11}$ refers to this issue as the in-

9 This approach was earlier pursued in many works including: A.D. Moore Intellectual Property and Information Control, London 2004; and J. Wilson, 'Could There Be a Right to Own Intellectual Property?', Law and Philosophy 28 (2009), pp. 393-427.

10 Examples 1-2 are adapted from: W. Gamrot, The Type-Token Distinction and Four Problems with Propertarian IP Justifications.

11 D. Attas, 'Lockean Justifications of Intellectual Property,' [in:] Intellectual Property and Theories of Justice, A. Gosseries, A. Strowel, A. Marciano (eds.), New York 2008, pp. 29-56. The problem is also recognized in the paper: S. Stercx, 'The Moral Justifiability of Patents,'Ethical Perspectives 13 (2006), pp. 249-265. 
dividuation problem. He argues that it is a major obstacle in justifying IP regimes on Lockean grounds. In what follows, this issue is explored further.

\section{The Dissimilarity Threshold}

As the ownership of exact types is unpractical, and the ownership of the all-embracing super-type would entail a right of complete control over the whole universe, it might reasonably be expected that IP advocates will call for some middle-ground solution between these two extremes. An intuitive approach would be to prohibit all material structures which are similar enough to the one embodied in an "original" first token, a material prototype of invention, or a precise description of an innovation. Those which are not sufficiently similar would not be prohibited. Hence it must be determined, which differences between structures are sufficiently small for them to be treated as tokens of the same single type. This is illustrated by the example 2 .

EXAMPLE 2. An inventor comes up with a beneficial mix of substances $\mathrm{M}$ and $\mathrm{N}$ in the proportion $f=0.6$ and wants to appropriate a type covering all mixes where the proportion $f^{\prime}$ of the two ingredients is similar to $f$. Should the difference threshold be 0.01 , resulting in a range of prohibited values corresponding to the interval $[0.59,0.61]$ ? Or should it perhaps equal 0.03 , with an associated range of $[0.57,0.63]$ ?

An increase of the threshold will expand the set of prohibited structures and hence benefit the innovator or artist. Its decrease will benefit others. However there is an uncountable continuum of positive threshold values to choose from and there is no intrinsic reason to prefer any one of them.

\section{Measuring Dissimilarity}

Difficulties in establishing type boundaries are not limited to the location of a threshold. Material structures are characterized by numerous features. Even if these features are of the same nature and may be conveniently described by simple vectors of numbers (say $X=\left[x_{1}, \ldots, x_{\mathrm{k}}\right], Y=\left[y_{1}, \ldots, y_{\mathrm{k}}\right]$ ) one still needs to decide how to measure the dissimilarity between such structures. The mathematical theory of vector spaces and vector norms provides only a very limited guidance: the formula for a distance between two vectors only needs to satisfy certain regularity conditions, known as triangle inequality, absolute homogeneity and point separation. This still allows for a huge number of valid distance formulas including, but not limited to, the Manhattan distance:

$$
L_{1}(X, Y)=\sum_{i=1}^{k}\left|x_{i}-y_{i}\right|
$$

the Euclidean distance:

$$
L_{2}(X, Y)=\sqrt{\sum_{i=1}^{k}\left|x_{i}-y_{i}\right|^{2}}
$$


and the Minkowski distance:

$$
L_{\alpha}(X, Y)=\left(\sum_{i=1}^{k}\left|x_{i}-y_{i}\right|^{\alpha}\right)^{1 / \alpha}
$$

which is a generalization of the first two (for $\alpha=1,2$ ) but also allows for any value of $\alpha$ in $[1,+\infty)$ resulting in an infinite number of acceptable distance formulas. Distances calculated through them may be different and differently ordered. This is illustrated by the example 3 .

EXAMPLE 3. Let a beneficial mix P consist of three substances (say L, M and N) such that two parts of $\mathrm{L}$ are mixed with three parts of $\mathrm{M}$ and five parts of $\mathrm{N}$. The mix is exhaustively characterized by a vector $\mathbf{f}_{\mathrm{P}}=\left[f_{1}, f_{2}\right]=[0.2,0.3]$ describing shares $f_{1}, f_{2}$ of $\mathrm{L}$ and $\mathrm{M}$, with $\mathrm{N}$ constituting the rest. Three other mixes $\mathrm{A}, \mathrm{B}$, and $\mathrm{C}$ are described by vectors $\mathbf{f}_{\mathrm{A}}=[0.34,0.40], \mathbf{f}_{\mathrm{B}}=[0.35,0.15]$, and $\mathbf{f}_{\mathrm{C}}=[0.20,0.50]$. Figure 1(a) presents all four mixes. Figures 1(b)-1(d) show equal distance contour lines for Manhat$\tan \left(L_{1}\right)$, Euclidean $\left(L_{2}\right)$ and Minkowski $\left(L_{3}\right)$ distance functions. For each formula, the distances of the three mixes from $\mathrm{P}$ are different, and their proximity orderings are respectively: $(\mathrm{C}, \mathrm{A}, \mathrm{B}),(\mathrm{A}, \mathrm{C}, \mathrm{B})$ and $(\mathrm{A}, \mathrm{B}, \mathrm{C})$, as shown in the table 1 . Depending on the distance formula, a mix may either be considered closer to the "original" or farther from it than others.
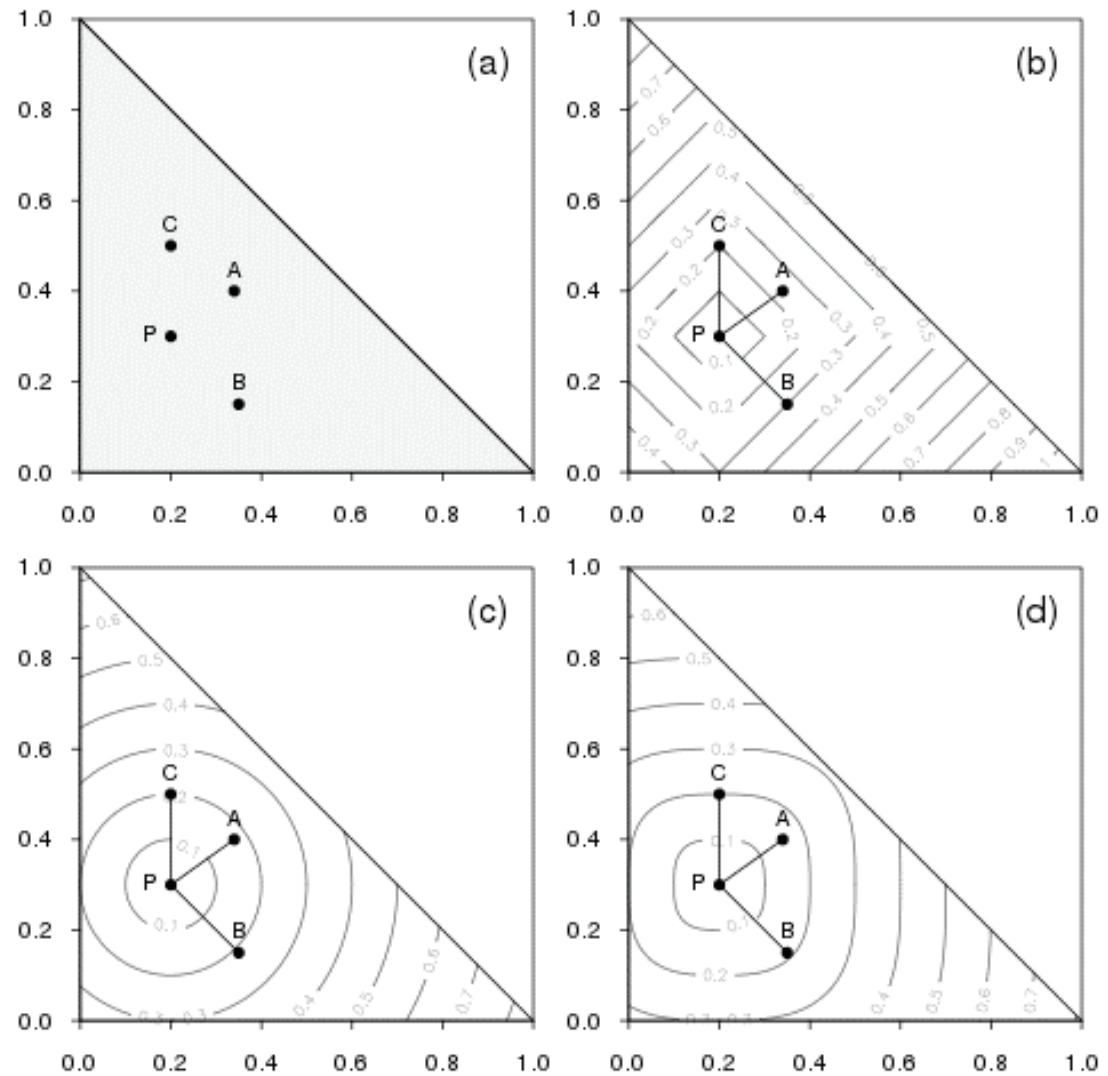
Figure 1. Graphical representation of mixes P, A, B, C and equal distance lines from $\mathrm{P}$ for three distance formulas

Table 1. Distances between mixes for various distance formulas

\begin{tabular}{|c|c|c|c|c|}
\hline$\alpha$ & $\mathrm{L}_{\alpha}(\mathrm{A}, \mathrm{P})$ & $\mathrm{L}_{\alpha}(\mathrm{B}, \mathrm{P})$ & $\mathrm{L}_{\alpha}(\mathrm{C}, \mathrm{P})$ & Proximity order \\
\hline 1 & 0.240 & 0.300 & 0.200 & $(\mathrm{C}, \mathrm{A}, \mathrm{B})$ \\
\hline 2 & 0.172 & 0.212 & 0.200 & $(\mathrm{~A}, \mathrm{C}, \mathrm{B})$ \\
\hline 3 & 0.155 & 0.189 & 0.200 & $(\mathrm{~A}, \mathrm{~B}, \mathrm{C})$ \\
\hline
\end{tabular}

Varying proximity orderings exacerbate the individuation problem. There is no intrinsic reason to prefer any distance formula to others. By arbitrarily choosing among them one decides at whose expense the type will be appropriated and whose property rights in material objects will be restricted to make space for IP. This is a particularly disturbing circumstance if the decision is taken after competitors have already started the work on their material structures. The choice of a distance function may amount to selecting which one of them will be forced to abandon the investment and all associated sunk costs.

\section{Equivalent Characterizations}

Even if a universal agreement is somehow reached on using a particular distance formula and dissimilarity threshold, the "original" exact type or corresponding material structure may be exhaustively described in numerous equivalent ways, still resulting in varying proximity orderings. This is illustrated by example 4 .

EXAMPLE 4. Consider the mixes A, B, C, and P from the previous example. Let the Euclidean formula be somehow universally agreed upon as a distance measure. All mixes may be characterized by shares $f_{1}$ and $f_{2}$ of ingredients $\mathrm{L}$ and $\mathrm{M}$. However one may equally precisely characterize the mix by specifying shares $f_{2}$ and $f_{3}$ of $\mathrm{M}$ and $\mathrm{N}$, or by specifying shares $f_{1}$ and $f_{3}$ of $\mathrm{L}$ and $\mathrm{N}$. Each of these three characterizations defines proportions of all three ingredients and is sufficient to reproduce the mix. Resulting Euclidean distances between $\mathrm{P}$ and other mixes are shown in the table 2. For the three descriptions $\left[f_{1}, f_{2}\right],\left[f_{1}, f_{3}\right]$ and $\left[f_{2}, f_{3}\right]$ the order of proximity is respectively (A,C,B), $\left.\mathrm{B}, \mathrm{C}, \mathrm{A}\right)$ and $(\mathrm{B}, \mathrm{A}, \mathrm{C})$.

Table 2. Euclidean distances for various characterizations of mixes

\begin{tabular}{|c|c|c|c|c|}
\hline Variables & $\mathrm{L}_{2}(\mathrm{~A}, \mathrm{P})$ & $\mathrm{L}_{2}(\mathrm{~B}, \mathrm{P})$ & $\mathrm{L}_{2}(\mathrm{C}, \mathrm{P})$ & Proximity order \\
\hline$\left[f_{1}, f_{2}\right]$ & 0.17 & 0.21 & 0.20 & $(\mathrm{~A}, \mathrm{C}, \mathrm{B})$ \\
\hline$\left[f_{1}, f_{3}\right]$ & 0.28 & 0.15 & 0.20 & $(\mathrm{~B}, \mathrm{C}, \mathrm{A})$ \\
\hline$\left[f_{2}, f_{3}\right]$ & 0.26 & 0.15 & 0.28 & $(\mathrm{~B}, \mathrm{~A}, \mathrm{C})$ \\
\hline
\end{tabular}

The example shows that even if everyone is somehow convinced that a particular distance function and threshold are the right ones, the problem of varying proximity orderings is not alleviated. The type may be characterized in numerous ways of which every one is sufficient to reproduce tokens and hence equally valid. The choice of a particular characterization of the "original" structure, from among numerous equivalents, does not follow from any intrinsic properties of types and cannot 
be explained by anything in their nature. ${ }^{12}$ By arbitrarily choosing among them one still decides which structures embody the type and at whose expense it will be appropriated. This is illustrated by the example 5 .

EXAMPLE 5. Let the threshold of 0.18 be somehow universally agreed upon in the example 4 . Describing the mix $\mathrm{P}$ by variables $\left[f_{1}, f_{2}\right]$ would eliminate from the market the competitor who started working on the mix A. The other two options: $\left[f_{1}, f_{3}\right]$ and $\left[f_{2}, f_{3}\right]$ leave him undisturbed, but eliminate from competition those already experimenting with the mix $\mathrm{B}$.

The problem of choosing among possible characterizations is not alleviated by postulating that all possible characteristics should be considered, guided by a simple intuition that a triple of $f_{1}, f_{2}$ and $f_{3}$ perhaps exhausts the possibilities. It does not. Even the trivial mix in our example may be described in many more ways, for example by specifying various combinations of ratios: $f_{1} / f_{2}, f_{2} / f_{3}, f_{1} / f_{3}, f_{2} / f_{1}, f_{3} / f_{2}$, $f_{3} / f_{1}$, differences: $f_{1}-f_{2}, f_{1}-f_{3}, f_{2}-f_{3}$ and other kinds of arithmetic relations. The number of all possible descriptions is usually too large to process or simply infinite, preventing a formal disproval of imitation.

\section{The Base of Comparison}

The problems described in the previous section are accompanied by another critical circumstance. So far, it was tacitly assumed that material structures in question are already identified, and their borders clearly delineated. However, for the IP to remain enforceable in practice, one also has to account for cases of partial reproduction. It may happen that the material structure is not copied in its entirety, but only some parts of it are. An imitator may choose to incorporate in his own work only a subset of the prohibited structure. Omitted parts may be replaced with other objects. Additional items may be attached reducing the share of repeated content. To detect such cases, one would have to compare subsets of both structures in question. This brings at least two challenges.

Firstly, if the two structures consist of numerous components, then the number of subsets to be compared may be astronomically large, preventing exhaustive enumeration and comparisons. This is illustrated by the example 6 :

EXAMPLE 6. If the original material structure consists of a mere 50 identifiable items, then a total of $2^{50}-50-2$ proper subsets of two or more elements may be identified. If the suspected partial imitation also consists of 50 elements, then the number of same-size subset pairs to be compared exceeds $10^{29}$.

Large structures contain great numbers of components. Due to the combinatorial explosion, enumeration of all their subsets, that is needed to disprove imitation may be impossible even if all relevant data are fed into a computer.

A second problem also arises. When the search for similarities proceeds to smaller and smaller subsets of the structure, at some point it will reach very simple ones.

12 Interestingly, the existence of numerous candidate conventions, of which none is obviously better than the others and the fact that their choice is undetermined by the nature of things happens to coincide with some basic tenets of a more general conventionalist viewpoint. See e.g. M. Rescorla, 'Convention,' The Stanford Encyclopedia of Philosophy (Summer 19 Edition), E.N.Zalta (ed.). 
The simpler the subset, the more likely it is to be found embodied somewhere. Subsets which are very basic will be identified everywhere. The consequences of declaring that the repetition of any subsets amounts to unauthorized imitation may be summarized by the words of Jakub Bożydar Wiśniewski:

Taken to its ultimate conclusion, such an approach would paralyze all human action, destroying humankind almost on the spot by making everyone unsure of whether engaging in perfectly mundane activities violates someone else's intellectual property rights. ${ }^{13}$

To solve both problems, the range of compared subsets must inevitably be restricted, so that some of them — in particular the simplest ones — are eliminated from comparisons. A theory must be proposed that would explain why some subsets should be compared while others should not. The problem is illustrated by the example 7 .

EXAMPLE 7. Let Tom come up with a beneficial mix P of five substances (say J,K,L,M,N) in equal proportions 1:1:1:1:1. Then let Alice come up with another mix of these substances in the proportions $7: 7: 2: 2: 2$. Is her use of the sub-mix of $\mathrm{L}, \mathrm{M}, \mathrm{N}$ in the proportion $2: 2: 2$, (equivalent to $1: 1: 1$ in Tom's mix) an infringement? Is the use of the sub-mix of J and $\mathrm{K}$ in the proportion 7:7 (again equivalent to 1:1) an infringement? Is Tom right when he claims that Alice violated his rights to the original mix of J,K,L,M,N in proportions 1:1:1:1:1 by using it as an ingredient amounting to $50 \%$ of her mix, supplemented by extra quantities of $\mathrm{J}$ and $\mathrm{K}$ ?

Anyone might come up with an ad-hoc rule, perhaps stating that the sub-mix of four ingredients is a repetition significant enough for a valid accusation of IP violation while the submix of three is not sufficient. Someone else might propose an alternative rule stating that the violation occurs when more than $20 \%, 40 \%$ or perhaps $60 \%$ of the mix is the same. However there is again nothing in the nature of types that would justify the choice of any such rule over others. There is no underlying empirical reality that could be consulted to verify whether two material structures which are perhaps similar but not identical, indeed embody the same type.

\section{The Three Dimensions of Type Individuation}

Examples presented so far focused on a very simple model case of substance mixing. However, when more complex structures are considered, the same difficulties appear. The problems identified in preceding sections need to be addressed. This requires systematic answers to three questions:

(1) which material structures and which of their subsets should be compared?

(2) which of their characteristics should be accounted for?

(3) how to combine these characteristics into a decision rule for token identification?

These may be posed with respect to types in any branch of IP. In this section a few particular situations are briefly mentioned.

13 J.B., Wiśniewski, 'On the Impossibility of Intellectual Property', Quarterly Journal of Austrian Economics 23 (2020), pp. 33-45. 
Mechanical devices, engineering and architectural designs typically consist of numerous items, which leads to astronomically large numbers of subsets. It is not obvious how large or how complex such a subset should be in order to be compared. Moreover, even if the structures are by some miracle uniquely defined, then their description usually includes complex systems of geometric forms. It is often not obvious how they should be compared. Even the simplest shapes may be described in numerous ways. The triangle, which appears in most engineering designs, may be described by specifying (a) three side lengths (b) one angle and two adjacent side lengths (c) two angles and the side length between them (d) two angles and the triangle area (e) two angles and the triangle perimeter (f) the base, altitude and foot (g) coordinates of vertices in various coordinate systems. The list is certainly incomplete even for such a simple shape. Combined with a large number of components and their relations to be described, this results in huge numbers of possible equivalent characterizations. It is not obvious, which characterization should be chosen, how to compare the structures and how to draw a conclusion.

The field of integrated circuit technologies presents similar challenges. It is not obvious why any part of such a system should be considered large enough, or complex enough to be compared while others are not. There does not even seem to be an universally accepted measure of complexity that would fit all the various structures. To make matters worse, complexity does not seem to be a simple function of component quantity. It is not obvious at all that an RCA1802 microprocessor containing mere 5000 transistors, which controls several spacecraft, satellites and the Hubble telescope is less complex than a modern RAM chip which stores information in millions of them. It is not obvious how to choose characteristics of such a system to be compared, how to aggregate them and form a decision rule.

Difficulties posed by computer programs are no less demanding The meaning and content of statements is different for hundreds of diverse programming languages and hardware environments. Not only it is not obvious how long the sequence of programming statements should be, in order to be subject to comparisons, but also it is not obvious which statements should be included. The code may be reordered, interleaved with other code or replaced with functional equivalents. It may also be subject to automatic optimization and modularization, that make it similar to existing programs even without programmer's knowledge. It is not obvious which fragments of the code - continuous or not - are long, complex, or "original" enough to be compared. It is not obvious what measure of similarity should be employed for comparisons. Should it be based on the number of repeated statements? Or the number of repeated statement pairs? Maybe the longest repeated sequence? What kind of threshold should be applied to each such situation and why not higher or lower? Similar problems reappear in other IT-related contexts, such as measuring similarity between algorithms or database structures.

One is confronted with the same three questions when it comes to artistic works. A typical example is a written text such as a book, a poem or song lyrics. It is not obvious how large the fragment of text should be in order to be compared, whether it might be discontinuous or not, and how many discontinuities could eventually be allowed. It is equally unclear whether the dissimilarity measure should be based on 
the number of repeated letters or words, whether the calculation should account for synonyms and what could eventually be considered a synonym in any given context. The same problems appear if plots of artistic works are compared. Is naming the character "Aragorn" sufficient to declare that the book trespasses on Tolkien's famous classic? Perhaps "Aragorn" and "Gandalf" will suffice? What about "Eregorn" and "Eandalf"? Does it matter if Gandalf is a goblin? By the same token, it is not obvious which parts of melodies, photos, and films are large or complex enough to be subject to comparison. It is not obvious how to choose their relevant characteristics, and how to translate their values into token recognition decisions.

Some objects are especially difficult to formally compare. Sculptures, boat hull shapes and car coachworks are often too irregular to be described exhaustively by a short list of variables. The number of various measurements that could be recorded and compared for them may be practically unlimited. If one decides to choose only a subset of variables, then there is no natural guidance on their relative importance that could facilitate the selection. Such decisions cannot be easily generalized from one individual case to others. Moreover, there is no obvious way of decomposing sculptures, boat hull shapes, paintings and dances into parts that could be compared in a hunt for partial imitation. The number of ways in which monolithic structures could be conceptually split into pieces is practically unlimited. Possible cuts form a multidimensional continuum. Exhaustive examination is not feasible which rules out a formal disproval of partial copying. Even with the complete knowledge of an "original" token, no one can be certain of not violating others' IP rights.

\section{Auxiliary Information}

The discussion above concentrated on the problem of type definition under the assumption that only the "original" material structure, or its detailed description are known. This foundation may be extended by including auxiliary information about a wider context and circumstances where that structure might be deployed. Token usefulness may be accounted for when setting up type boundaries. It may be postulated that they be defined in such a way that all exact material structures corresponding to boundary points are in some sense significantly worse than the "original."14 The type might correspond to a continuous area in the space of logical possibilities that includes the exact configuration of an instantiated "original" material object and all other configurations for which some utility measure exceeds some minimal threshold. ${ }^{15}$ This might seem to be a promising way of reducing subjectiveness and alleviating the problem (3) stated in the previous section. But a closer inspection reveals serious flaws in the proposal.

Firstly, it is usually not obvious how to construct the utility measure that would reflect the usefulness, attractiveness, desirability or benefits of material items. Even

14 I am grateful to an anonymous Reviewer for drawing my attention to this possibility .

15 The threshold might be set at zero, reflecting total uselessness, or at some fraction of the "original" quality. 
if a given material structure is only used to attain a single objective, its advantages may be expressed in many ways. This is illustrated by the example 8 .

EXAMPLE 8. Let the mix of substances considered in examples 1-7 be a disinfectant. Its role is simple: to eradicate unwanted microorganisms. The more of them are killed, the better. However results of applying the mix will vary due to uncontrollable environmental factors and unavoidable microscale variation of biological processes. The number of eliminated germs may be considered a random variable that obeys some probability distribution. The tendency to take higher or lower values may be characterized by various quantities known as location parameters. These include the expectation, the mode, moments, quantiles of various orders and many others. It is not obvious, which parameter should be chosen. The selection will certainly affect type boundaries and there is no obvious best choice. Moreover, the mix may be delivered by various methods and in various circumstances on which its efficiency depends in complex ways. One has to choose the method of application (spraying, aerosolizing, painting, dissolving, etc), time of exposure, lighting conditions, temperature, humidity and several other factors. Obviously all of these choices affect parameter estimates, indirectly influencing type boundaries, and there is no intrinsic reason to choose any of them, as disinfectants are applied in a wide range of conditions.

The translation of utility into numbers runs into other problems as well. Benefits of various kinds of objects are difficult to express numerically. Perceptions of these benefits may only take form of preference relations of the form "A is better than B". For artistic works, an object that is deemed inferior to the one in question may always be found, so measurement scale for a variable that reflects attractiveness would have no zero point. Besides, aesthetic preferences vary among individuals and aggregating them is purely subjective. These problems are not limited to artistic works and plague various other types describing painkillers, garments, jacuzzi designs, or car seats.

A second problem for the proposed approach also arises. Apart from the simplest cases where the utility is expressed by known mathematical formulas enabling formal manipulation, evaluation of hypothetical material structures may be challenging. This happens when the data comes from observation of, or experimenting with complex systems featuring intricate dependencies. It is not possible to experimentally assess all the possible configurations defined by many real-valued parameters. Only a finite number may be examined. Observations may also be distorted by stochastic disturbances and measurement errors. To assess properties of hypothetical configurations some kind of extrapolation modelling must be applied. Further nonobvious decisions are hence required, as there is no universal mathematical model that would fit any system, and the number of candidate models is infinite. This obviously affects extrapolation results thereby influencing type boundaries ${ }^{16}$ as sketched in the example 9 .

EXAMPLE 9. Let us generously assume that problems with constructing the utility measure in the example 8 are somehow overcome and that it is generally agreed that disinfectant efficiency should simply be characterized by an expected percentage (EP) of eliminated microorganisms. However, for

16 Employing goodness-of-fit criteria to model selection mitigates this problem only partially, because various fit criteria, risk functions, regularity conditions, bandwith selection methods, outlier elimination algorithms and the like may lead to selection of different models. Mitigation possibilities depend on sample size. For a single data point they vanish. The choice is unavoidable, whether it refers to models or to underlying tacit assumptions. 
technical reasons - say limited availability of isolated live germs to experiment on - the EP is calculated only for one mix of substances characterized by an ingredient proportion vector $\mathbf{f}_{1}=[0.3,0.3]$ and it equals 0.9 . In order to decide if the mix described by vector $\mathbf{f}_{2}=[0.28,0.34]$, belongs to the same type as $\mathbf{f}_{1}$, the EP value for $\mathbf{f}_{2}$ should be assessed. There are multiple ways of carrying out an educated guess, but no intrinsic reason to prefer any single one of them. The problem will not vanish when greater, but unavoidably finite number of mixes is experimented on.

There is also a third difficulty. Even if everyone somehow agrees on the way of expressing numerically desired features of tokens and extrapolating them to hypothetical structures, there are usually many characteristics of interest, so it must be decided which ones should be chosen and how they should be aggregated into a single measure of utility. This is illustrated by the example 10 .

EXAMPLE 10. Continuing examples 8 and 9, let us note that human environment is infested with thousands of bacteria and viruses species capable to a varying extent of infecting and causing harm. Therefore if the mix is to be considered useful, it should eliminate a wide range of microorganisms. In order to assess its benefits one would have to account for its EP characteristics against various species. Several problems immediately arise. Firstly, it is not technically feasible to assess EP for all germs: there are too many species and new ones are routinely reported. A subset must be chosen and it is not obvious how many and which species should be included. Secondly, when EP values are assessed, there are infinitely many possible ways of aggregating these individual indicators into a single measure of disinfection effectiveness. Again, there is no natural guidance which formula should be chosen from an infinite set of possible candidates. All these nonobvious decisions affect type boundaries. ${ }^{17}$ And on another level, the situation is repeated. Even if it is somehow agreed on how to calculate an objective measure of disinfectant effectiveness, there are numerous other features of the mix that are of interest. It matters how long the mix remains effective, how deep it penetrates various surfaces, how safe it is for humans, animals or plants. It has to be decided if and how all these factors are to be accounted for in the general measure of utility. ${ }^{18}$ Finally, one has to choose the threshold level that would separate useful enough and not-useful enough mixes, and thereby define type boundary.

The reasoning presented in this section may be summarized as follows. Attempts at avoiding one difficulty associated with the arbitrary selection of distance formula, by accounting for utility, lead to even more serious problems. One has to take several nonobvious decisions including: choosing those aspects of the structure that are of interest, choosing how to quantify them, choosing, if needed, how to extrapolate these assessments to hypothetical structures, choosing how to aggregate resulting indicators into a single utility measure, and choosing the minimum quality threshold. Therefore, accounting for token desirability, attractiveness, or benefits increases the subjectivity of type definition instead of reducing it. Questions (1), (2) and (3) have no objective answer.

\section{Conclusions}

The analysis presented above does not exhaust the list of IP-related quandaries which are not resolved by appealing to the nature of types. More of them may be

17 In addition, there is no unassailable way of identifying species. This is another nested type individuation problem: how many elements of genome have to be different (and which) for the two organisms to be considered distinct species. The individuation problem becomes recursive.

18 In particular, one has to decide, how much weight should be assigned to each variable. 
identified. These include the duration of IP rights, ${ }^{19}$ the scope of allowances associated with fair use or scientific experiments as well as criteria for eventual recognition of an independent invention. ${ }^{20}$ Legal regulations may be reasonably expected to involve more arbitrary choices. However the three discussed dilemmas seem to be unavoidable in any branch and any formulation of IP. They constitute a formidable challenge for any IP justification theory, and in particular for non-consequentialist ones.

Most importantly, simplistic approaches to type individuation that rely on quantifying the value of innovators' or artists' contribution, such as the proposal of Alfred Yen, ${ }^{21}$ are hopelessly inadequate. This is because the individuation problem, considered in all its three dimensions, is not only quantitative but also qualitative. Even if it is somehow established and agreed upon, how valuable that contribution is, and how large the area, volume or measure of the prohibited region should be, the boundaries of such a region may still be drawn in an infinite number of ways, and there is no intrinsic reason to prefer any one of them. The arbitrariness cannot be avoided.

It is widely believed, that for any legal system to be just, several basic requirements should be satisfied. One of these is the nullum crimen sine lege principle. It forbids punishing individuals for actions which are not explicitly prohibited by law. Another closely related and widely respected principle is the lex retro non agit postulate which forbids retroactive changes to the law. A legal system which does not respect them effectively turns any action into a gambling exercise. For the IP regulation to satisfy these requirements, type boundaries must be defined at the time of its appropriation, and their definition must be precise enough to decide whether any given material structure embodies the type or not. Otherwise, competitors of type's owner who assemble their material structures and invest in productive capacity might rightfully claim that an eventual later enactment of prohibition would violate both principles and hence it is unjust.

The investigation presented in this paper clearly shows that even the access to the token of a type that is already owned by someone else is insufficient for entrepreneurs or artists to identify boundaries of that type. A multitude of diverse subjective views on their location cannot be reconciled by consulting any objective empirical reality. Mere references to general clauses like "significant similarity" or "similitude" 22 cannot be considered boundary definitions because there is no universal consensus on what exactly these terms mean. If written into the law without precise explanation, they only mask the indeterminacy of boundaries. In difficult

19 J. Boyle, The public domain: Enclosing the commons of the mind, New Heaven-London 2008, p. 29. See also: J. Varelius, 'Is the Expiration of intellectual Property Rights a Problem for Non-consequentialist Theories of Intellectual Property?', Res Publica 20 (2014), pp. 345-357.

20 H. Breakey, 'Liberalism and Intellectual Property Rights,' Politics, Philosophy and Economics 3 (2009), pp. 329-349.

21 A.C. Yen, 'Restoring the Natural Law: Copyright as Labor and Possession,' Ohio State Law Journal 51 (1990), pp. 517-559.

22 W.J. Gordon, 'Intellectual Property Law,' [in:] Oxford Handbook of Legal Studies, P. Cane, M. Tushnet (eds.), Oxford 2003, pp. 617-646. 
cases such as the comparison of sculptures it is not obvious if such a precise definition is feasible at all. But even if it is, then IP regulation necessarily requires institutions that would define boundaries of owned types, keep records of these boundaries, dictate them to the general population and enforce the prohibition. Hence IP could not originate or exist in a prelegal state of nature.

Moreover, even if the IP regulation is deliberately intended at maintaining stability (e.g. by respecting earlier precedents) it will never be stable. This is because constant development of new technologies and new ways of expression requires repeated redefinition of IP boundaries with respect to all the three dilemmas discussed in preceding paragraphs. It is inconceivable that anyone could predict now, which subsets of material structures embodying future inventions or works of art will be chosen for comparisons, which of their characteristics will be considered important, how they will be aggregated and how these aggregates will be interpreted. This is because these technologies and works of art are not known yet and it is not known what they will consist of. By the same token, also contemporary regulations and restrictions were not known a few centuries earlier, when no one predicted that at some point the humanity will get access to antibiotics, transistors, computers and films. The progression of technology and arts requires constant extensions of IP regulations. ${ }^{23}$

The lack of natural foundations for type boundaries undermines some prominent justifications of IP. Several authors maintain that IP rights are natural rights and that they have always been recognized as such. Such claims may be found in the works of numerous scholars. ${ }^{24}$ However, to be considered natural, the right in question must be universal. ${ }^{25}$ It must be binding independently of space and time, while remaining obvious to anyone and easily recognized without intervention of political institutions. This is clearly contradicted by the indeterminacy of type boundaries and the necessity to draw them anew when previously unknown innovative technologies or pieces of art appear. The view of IP as a timeless natural right is therefore untenable. The proper designation for IP regulations, whose extent is defined

23 This effect is especially pronounced if type definitions rely on token usefulness. Context information is never stable. Apart form gradual expansion of technical knowledge, other circumstances affecting the decision, such as current needs and available resources, vary in time as well, forcing incessant recalculation of type boundaries.

24 Works that refer to Lockean (or natural rights) IP justification include among others J.W. Child, 'The moral foundations of intangible property,' [in:] Intellectual property: moral, legal, and international dilemmas, A. Moore (ed.), Lanham 1997, pp. 57-80; A. Mossoff, 'Locke's Labor Lost,' The University of Chicago Law School Roundtable 9 (2002), pp. 155-164. A. Mossoff, 'Is Copyright Property?,' San Diego Law Review 29 (2005), pp. 29-44. R.A. Epstein, 'Liberty versus Property? Cracks in the Foundations of Copyright Law,' San Diego Law Review 42 (2005), pp. 1-40. L. Zemer, 'The Making of a New Copyright Lockean,' Harvard Journal of Law 63 Public Policy 29 (2006), pp. 891-947. A. Mossoff, 'Saving Locke from Marx: the Labor Theory of Value in Intellectual Property Theory,' Social Philosophy and Policy 29 (2012), pp. 283-317; J.V. DeLong, 'Defending Intellectual Property,' [in:] Copy Fights, The Future of Intellectual Property in the Information Age, A. Thierer, C.W. Crews (eds.), Washington 2002, pp. 17-36.

25 J.B. Wiśniewski, Libertarian Quandaries, Published by Jakub Bożydar Wiśniewski 2016. 
on an ongoing basis by arbitrary decisions of political authorities, is not property, but a monopolistic privilege.

\section{References}

Attas D., 'Lockean Justifications of Intellectual Property,' [in:] Intellectual Property and Theories of Justice, A. Gosseries, A. Strowel, A. Marciano (eds.), New York 2008, pp. 29-56.

Bell A., Parchomovsky G., 'A Theory of Property,' Cornell Law Review 90 (2005), pp. 531-615.

Bell T., 'Copyright as Intellectual Property Privilege,' Syracuse Law Review 58 (2007), pp. 523-546.

Bell T., Intellectual Privilege, Arlington 2014.

Biron L., 'Two Challenges to the Idea of Intellectual Property,' Monist 93 (2010), pp. $382-394$.

Błaszczyk C., 'Lockean intellectual property refuted,' Scientia Politica 32 (2020), pp. 161-186.

Boldrin M., Levine D.K., Against Intellectual Monopoly, Cambridge 2008.

Boyle J., The Public Domain: Enclosing the commons of the mind, New Heaven-London 2008.

Breakey H., 'Liberalism and Intellectual Property Rights,' Politics, Philosophy and Economics 3 (2009), pp. 329-349.

Breakey H., 'Natural intellectual property rights and the public domain,' The Modern Law Review 73 (2010), pp. 208-239.

Child J.W., 'The moral foundations of intangible property,' [in:] Intellectual Property: Moral, legal, and international dilemmas, A. Moore (ed.), Lanham 1997, pp. 57-80.

DeLong J.V., 'Defending Intellectual Property,' [in:] Copy Fights, The Future of Intellectual Property in the Information Age, A. Thierer, C.W. Crews (eds.), Washington 2002, pp. 17-36.

Dodd J., 'Musical Works: Ontology and meta-ontology,' Philosophy Compass 3 (2008), pp. $1113-1134$.

Dodd J., 'Musical Works as Eternal Types,' British Journal of Aestethics 40 (2000), pp. $424-440$.

Dodd J., Works of Music: An Essay in Ontology, Oxford 2007.

Dominiak Ł., 'Anarcho-Capitalism, Aggression and Copyright,' Political Dialogues 16 (2014), pp. 37-47.

Drahos P., A Philosophy of Intellectual Property, Ashgate 1996.

Epstein R.A., 'Liberty versus Property? Cracks in the Foundations of Copyright Law,' San Diego Law Review 42 (2005), pp. 1-40.

Fisher W., 'Theories of Intellectual Property,' [in:] New Essays in the Legal and Political Theory of Property, S. Munzer (ed.), Cambridge 2001, pp. 168-199.

Gamrot W., 'On type creation and ownership,' Political Dialogues 30 (2021), pp. 187200. 
Gamrot W., 'The Type-Token Distinction and Four Problems with Propertarian IP Justification,' Axiomathes (2021); https://doi.org/10.1007/s10516-021-09564-5.

Gordon W.J., 'Intellectual Property Law,' [in:] Oxford Handbook of Legal Studies, P. Cane, M. Tushnet (eds.), Oxford 2003, pp. 617-646.

Himma K.E., 'The justification for intellectual property: Contemporary philosophical disputes,' Journal of the American Society for Information Science and Technology 59 (2008), pp. 1143-1161.

Hughes J., 'The Philosophy of Intellectual Property,' Georgetown Law Journal 77 (1988), pp. 330-350.

Kinsella N.S., Against Intellectual Property, Auburn 2008.

Lambrecht M., 'On water drinkers and magical springs: Challenging the Lockean proviso as a justification for copyright,' Ratio Iuris 28 (2015), pp. 1-29.

Leggett W., Democratick Editorials: Essays in Jacksonian Political Economy, L.H. White (ed.), Indianapolis 1984.

Luper S., 'Natural resources, gadgets and artificial life,' Environmental Values 8 (1999), pp. $27-55$.

Moore A.D., Intellectual Property and Information Control, London 2004.

Moore A.D., 'Lockean Theory of Intellectual Property,' Hamline Law Review 21 (1997), pp. $65-108$.

Mossoff A., 'Is Copyright Property?', San Diego Law Review 29 (2005), pp. 29-44.

Mossoff A., 'Locke's Labor Lost,' The University of Chicago Law School Roundtable 9 (2002), pp. 155-164.

Mossoff A., 'Saving Locke from Marx: the Labor Theory of Value in Intellectual Property Theory,' Social Philosophy and Policy 29 (2012), pp. 283-317.

Palmer T.G., 'Are Patents and Copyright Morally Justified? The Philosophy of Property Rights and Ideal Objects,' Harvard Journal of Law and Public Policy 13 (1990), pp. 817-865.

Papaioannou T., 'Towards a critique of moral foundations of intellectual property rights,' Journal of Global Ethics 2 (2006), pp. 67-90.

Rescorla M., 'Convention,' The Stanford Encyclopedia of Philosophy (Summer 19 Edition), E.N. Zalta (ed.), https://plato.stanford.edu/archives/sum2019/entries/convention/.

Sandefur T., 'A Critique of Ayn Rand's Theory of Intellectual Property Rights,' The Journal of Ayn Rand Studies 9 (2007), pp. 139-161.

Stercx S., 'The Moral Justifiability of Patents,' Ethical Perspectives 13 (2006), pp. 249-265.

Tucker B., Individual Liberty, New York 1924.

Uszkai R., 'Are Copyrights Compatible with Human Rights?', The Romanian Journal of Analytic Philosophy 8 (2014), pp. 5-20.

Uszkai R., 'Intellectual Property Has No Personality', Annals of the University of Bucharest Philosophy Series 66 (2017), pp. 181-205.

Uszkai R., 'The Use of Torrents in Society,' Libertarian Papers 10 (2018), pp. 181-210.

Varelius J., 'Is the Expiration of intellectual Property Rights a Problem for Non-consequentialist Theories of Intellectual Property?', Res Publica 20 (2014), pp. 345-357. 
Wilson J., 'Could There Be a Right to Own Intellectual Property?,' Law and Philosophy 28 (2009), pp. 393-427.

Wilson J., 'Ontology and the Regulation of Intellectual Property,' Monist 93 (2010), pp. $450-463$.

Wiśniewski J.B., Libertarian Quandaries, Published by Jakub Bożydar Wiśniewski, 2016.

Wiśniewski J.B., 'On the Impossibility of Intellectual Property,' Quarterly Journal of Austrian Economics 23 (2020), pp. 33-45.

Yen A.C., 'Restoring the Natural Law: Copyright as Labor and Possession,' Ohio State Law Journal 51 (1990), pp. 517-559.

Zemer L., 'The Making of a New Copyright Lockean,' Harvard Journal of Law \& Public Policy 29 (2006), pp. 891-947. 